\title{
THE PERCEPTION OF PATIENTS' RIGHTS AMONG BELGIAN POPULATION
}

\author{
Dirk Devroey ${ }^{1}$, Michel Deneyer ${ }^{2}$, Ellen Scheys ${ }^{1}$, Erwin Van De Vijver ${ }^{1}$, Lieve Van den Block ${ }^{1}$ \\ 'Department of Family Medicine, Vrije Universiteit Brussel, Brussels, Belgium \\ ${ }^{2}$ Department of Pediatrics, Vrije Universiteit Brussel, Brussels, Belgium
}

\begin{abstract}
SUMMARY
The aim of this study was to explore the knowledge and perception of specific patients' rights and the problems experienced with their fulfilment among the Belgian population. Participants were recruited through patient association groups and health insurance companies. They completed an Internet-based questionnaire with 20 questions concerning patients' rights. In total, 309 persons completed all questions. The mean age of participants was 46 years ( $S D=15), 58 \%$ of them were women. Participants judged patients' rights concerning the end of life $(88 \%)$, affordable health care (87\%) and information about health status $(85 \%)$ as the most important issues. Participants particularly showed concern about their legal rights for care offered in the patients' own language $(21 \%)$, euthanasia (15\%) and affordable health care (14\%). The most important problems experienced so far were related to care offered in the patients' own language (12\%), affordable health care (11\%) and access to their medical file (7\%).
\end{abstract}

Key words: patients' rights, legislation, jurisprudence, delivery of health care, end-of-life care, right to consent, right of privacy

Address for correspondence: D. Devroey, Department of Family Medicine, Vrije Universiteit Brussel, Laarbeeklaan 103, B-1090 Brussels, Belgium. E-mail: dirk.devroey@vub.ac.be

\section{INTRODUCTION}

In Belgium, as in most other countries, all inhabitants have rights with respect to the provision of medical care. These rights were codified into law on 22 August 2002. This law comprises the right to the quality of health care, the right to choose a care provider, the right to information about one's own health status including the right to perusal of medical files, the right to informed consent concerning diagnostic procedures and treatments, the right of privacy and the right to complaints mediation.

Other important patients' rights are determined by the law concerning the protection of persons with a mental illness (June 26, 1990), the law concerning abortion (April 3, 1990) and the law concerning euthanasia (May 28, 2002).

Belgium has two main linguistic groups, a Dutch-speaking group in the northern part and a French-speaking group in the southern part of the country. A small German-speaking region is located in the east. The capital city of Brussels is officially bilingual but is actually a mainly French-speaking enclave within the Dutch-speaking region. The right of medical care offered in the patients' own language is not laid down by law.

Compliance with relevant laws is only possible if health care providers and patients are well aware of their rights and there are no obstacles hampering the implementation of this legislation. A study of the Flemish patients' platform in 2004 showed that patients' representatives from different patients' organisations were not sufficiently informed about patients' rights (1). None of the respondents reported to have received any information concerning patients' rights from health care professionals at any time.

The 2004 annual report of the Belgian Service for Mediation on Patients' Rights stated that health care professionals were not cognizant of the relevant legislation (2). Most of the reported problems concerned communication, patients' information, the choice of a health care provider, the right to inspect or copy patient files, informed consent, and the quality of care provided. The same problems still emerged in the 2008 report of the same organisation (3). Especially in the case of surgeons several ethical issues persist, particularly concerning the poor application of patient's rights legislation and the difficult task to protect the privacy of patient's information (4).

In 2007, the Belgian government launched an information campaign about patients' rights. The campaign focussed on both patients and health care professionals. The aim was to familiarize them with the law concerning patients' rights and with the Belgian Service for Mediation on Patients' Rights. The same year, the number of reported problems relating to patients' rights increased by $64 \%$ compared to $2006(5,6)$. In 2008 , the number of complaints decreased by $11 \%$. It is not clear whether this decrease was due to better compliance with the laws or to underreporting.

The right to mediation is important to patients as well as to physicians. In a French study all complaints in a cardiology department were recorded during four years following the introduction of law on patients' rights in 2002. Almost one in three complaints was resolved by mediation and one in three resulted in litigation (7).

A study among almost 7,000 members of the Socialist Health Service shows that less than $50 \%$ of the patients were well aware of their patients' rights (8). They were not aware of having the right to inspect or copy their patient files and they did not know of the possibility to mediate their complaints related to hospital admissions. The study also showed that the law was not always respected. For instance, one in five patients' requests to inspect their medical files was refused. One in four patients was not sufficiently informed about treatment issues and $65 \%$ of them were not suf- 
ficiently informed about the cost of hospitalisation. Mainly elderly and socially disadvantaged patients were insufficiently informed. Although the results of this study were remarkable, it needs to be said that the study exclusively inquired into patients'perceptions while the findings were not objectivized by experts.

The aim of this study was to explore the knowledge and perception of 20 specific patients' rights and the problems experienced with their fulfilment, specifically in relation to the socio-demographic characteristics of respondents.

\section{MATERIALS AND METHODS}

\section{Design, Study Population and Procedures}

Participants were recruited through patient organisations and health insurance services. All patient organisations affiliated to the Flemish Patient Platform ( $\mathrm{n}=89$ ), the Walloon Federation of Patients' Associations $(n=193)$ and all health insurance services $(n=7)$ received an invitation to participate in the study, asking them to publish this invitation in their newsletter or to forward it to their members. This method of recruitment guaranteed that people from all walks of life had the opportunity to participate in the study. The participants completed an Internet-based questionnaire with 20 questions about patients' rights. The selected patients' rights correspond with the major topics of the Belgian laws on patients' rights, euthanasia, abortion, and the protection of persons with a mental illness. These laws apply to patients of all ages including children. However, the results of this study focus on adults only because the rights of children patients are very different from the rights of adults and the questioning of children requires a specific method and questionnaire.

The questionnaire was validated prior to the study. Internal consistency and reliability was good (Cronbach's alpha $=0.81$ ).

Each of the questions investigated the importance that patients accorded to a specific right, the protection they thought the right gave them and the problems they experienced with that specific right. The participants answered the questions using a Likert scale ranging from one to five. The score of one on the Likert scale corresponded with "very little" and the score of five corresponded with "very much". The surveyed rights included the right to dignified end of life, affordable health care, information about health status, euthanasia, quality health care, palliative care, informed consent for health care, informed consent for medical examinations, self-determination, abortion, respect for privacy, access to one's own patient file, free choice of hospital, complaints mediation, care offered in the patient's own language, free choice of family physician, protection of a person with a mental illness, free choice of specialist, protection of life, and finally, free choice of any care provider.

\section{Data Capturing Software}

We opted for an online questionnaire in Dutch (http://huis. vub.ac.be/patientenrechten/) and French (http://huis.vub.ac.be/ patientenrechten $/ \mathrm{F} /$ ). The questionnaire was translated from Dutch to French using the backward-forward method and additionally double checked by the authors and a translator. Processing was done using the digital platform of the Faculty of Medicine and Pharmacy (MINF) at Vrije Universiteit Brussel. The data were

Table 1. Importance of patients' rights

\begin{tabular}{|c|c|c|c|c|c|c|c|}
\hline & Mean & SD & Score $1(\%)$ & Score $2(\%)$ & Score $3(\%)$ & Score $4(\%)$ & Score $5(\%)$ \\
\hline Dignified end-of-life & 4.9 & 0.5 & 0 & 0 & 2 & 10 & 88 \\
\hline Affordable health care & 4.8 & 0.5 & 0 & 0 & 2 & 11 & 87 \\
\hline Information about health status & 4.8 & 0.5 & 0 & 0 & 3 & 12 & 85 \\
\hline Euthanasia & 4.8 & 0.6 & 1 & 0 & 4 & 11 & 84 \\
\hline Quality health care & 4.8 & 0.4 & 0 & 0 & 2 & 15 & 83 \\
\hline Palliative care & 4.8 & 0.5 & 0 & 0 & 1 & 16 & 83 \\
\hline Informed consent for treatment & 4.7 & 0.6 & 0 & 1 & 5 & 17 & 77 \\
\hline Informed consent for medical examinations & 4.7 & 0.7 & 0 & 1 & 6 & 17 & 76 \\
\hline Self determination & 4.7 & 0.6 & 0 & 1 & 6 & 18 & 75 \\
\hline Abortion & 4.6 & 0.9 & 2 & 1 & 8 & 14 & 75 \\
\hline Respect for privacy & 4.6 & 0.7 & 0 & 1 & 7 & 17 & 75 \\
\hline Access to the medical file & 4.6 & 0.9 & 2 & 2 & 8 & 15 & 73 \\
\hline Free choice of hospital & 4.5 & 0.8 & 1 & 2 & 7 & 20 & 70 \\
\hline Complaints mediation & 4.5 & 0.8 & 1 & 1 & 8 & 22 & 68 \\
\hline Care in patients' own language & 4.5 & 0.8 & 2 & 0 & 10 & 20 & 68 \\
\hline Free choice of family physician & 4.5 & 0.7 & 0 & 2 & 7 & 23 & 68 \\
\hline Protection of a person with a mental illness & 4.5 & 0.8 & 1 & 1 & 7 & 25 & 66 \\
\hline Free choice of specialist & 4.5 & 0.9 & 1 & 5 & 7 & 22 & 65 \\
\hline Protection of life & 4.3 & 1.0 & 2 & 3 & 15 & 21 & 59 \\
\hline Free choice of care provider & 4.3 & 0.9 & 0 & 5 & 16 & 26 & 53 \\
\hline
\end{tabular}


Table 2. Perceived protection by patients' rights

\begin{tabular}{|c|c|c|c|c|c|c|c|c|}
\hline & Mean & SD & Score $1(\%)$ & Score $2(\%)$ & Score $3(\%)$ & Score $4(\%)$ & Score $5(\%)$ & $\begin{array}{c}\text { Don't know } \\
(\%)\end{array}$ \\
\hline Free choice of family physician & 3.8 & 1.0 & 3 & 5 & 19 & 31 & 25 & 17 \\
\hline Protection of life & 3.7 & 1.1 & 4 & 5 & 21 & 25 & 21 & 24 \\
\hline Abortion & 3.7 & 1.1 & 3 & 8 & 20 & 29 & 22 & 18 \\
\hline Respect for privacy & 3.6 & 1.1 & 4 & 8 & 21 & 30 & 19 & 18 \\
\hline Free choice of care provider & 3.5 & 1.0 & 3 & 9 & 27 & 33 & 10 & 18 \\
\hline Quality health care & 3.5 & 1.0 & 4 & 7 & 29 & 32 & 12 & 16 \\
\hline Free choice of specialist & 3.5 & 1.2 & 6 & 10 & 22 & 27 & 17 & 18 \\
\hline Palliative care & 3.4 & 1.1 & 5 & 11 & 22 & 28 & 14 & 20 \\
\hline Information about health status & 3.4 & 1.1 & 5 & 11 & 27 & 31 & 13 & 13 \\
\hline Self determination & 3.4 & 1.1 & 5 & 10 & 28 & 24 & 13 & 20 \\
\hline Access to the medical file & 3.4 & 1.2 & 7 & 13 & 19 & 30 & 15 & 16 \\
\hline Informed consent for treatment & 3.3 & 1.1 & 4 & 15 & 24 & 29 & 11 & 17 \\
\hline $\begin{array}{l}\text { Informed consent for diagnostic } \\
\text { examinations }\end{array}$ & 3.3 & 1.1 & 5 & 13 & 27 & 28 & 11 & 16 \\
\hline $\begin{array}{l}\text { Protection of a person with a mental } \\
\text { illness }\end{array}$ & 3.3 & 1.1 & 7 & 7 & 25 & 23 & 10 & 29 \\
\hline Free choice of hospital & 3.3 & 1.3 & 10 & 11 & 20 & 25 & 15 & 19 \\
\hline Complaints mediation & 3.1 & 1.2 & 8 & 14 & 26 & 20 & 11 & 21 \\
\hline Dignified end-of-life & 3.0 & 1.2 & 12 & 18 & 23 & 18 & 11 & 18 \\
\hline Affordable health care & 2.9 & 1.2 & 14 & 20 & 25 & 21 & 11 & 9 \\
\hline Euthanasia & 2.9 & 1.3 & 14 & 20 & 21 & 20 & 11 & 14 \\
\hline Care in patients' own language & 2.6 & 1.3 & 21 & 17 & 23 & 14 & 7 & 18 \\
\hline
\end{tabular}

gathered by means of a Personal home page Hypertext Preprocessor (PHP) program and immediately stored in a Structured Query Language (SQL) database.

Several control measures ensured data quality and limited missing data. Data cleaning was performed in two steps: detection of errors in the dataset and correction of these errors. The data cleaning looked for missing data, typing errors on data entry, coding errors, systematic repetitive answers, discordant answers and errors related to misinterpretation of questions. Errors were detected by using descriptive statistics, scatter plots and histograms. Presence of systematic repetitive answers was considered when the same option was systematically answered in consecutive questions. These answers were considered as misleading and were not included in the analyses.

\section{Ethical Approval and Privacy}

The study protocol was approved by the Ethical Committee of the University Hospital of Brussels (UZ Brussel). Belgian ethical committees require approval for all studies on animals and humans. Therefore, ethical approval was obtained despite the fact that no interventions or any other invasive procedures were used. The participants could read an informed consent declaration online and they declared to agree with the informed consent before starting the questionnaire. It was up to the respondents to decide whether they would fill in the questionnaire or not.

The privacy of participants was guaranteed, no participant personal information was stored. The software prevented partici- pants from completing the questionnaire more than four times on the same computer. This feature was installed to limit improper use of the software by completing the questionnaire more than once. The possibility to participate up to four times gave each member of an average family the opportunity to participate in the study. The software required the participants to answer a question before another question was accessible. Analysis was performed only on the answers of participants who completed all questions.

\section{Statistical Analysis}

IBM SPSS Statistics for MAC 19® (SPSS Inc.,Chicago,Il,USA) was used for analysis and statistical processing. The means of scores on the Likert scales were calculated as well as their standard deviations (SD).

There is a potential for confounding since the studied sample of the population may differ from the whole Belgian population. In an effort to assess the potential for confounding, all rates were standardised for demographic variables such as age, gender, education, and area of living, adjusting for under- and overrepresented groups. The demographic data provided by the federal government were used for standardisation purposes (9). Because most of the participants lived in urban areas and received higher education, only the adjusted rates are presented in this paper.

Multivariate analyses were performed with backward stepwise logistic regression analysis to look at the association between demographic variables and the perceived importance of patients' rights, the perceived protection and the problems with patients' rights. 
Table 3. Perceived problems with patients' rights

\begin{tabular}{|c|c|c|c|c|c|c|c|}
\hline & Mean & SD & Score $1(\%)$ & Score $2(\%)$ & Score $3(\%)$ & Score $4(\%)$ & Score $5(\%)$ \\
\hline Affordable health care & 2.2 & 1.4 & 45 & 20 & 16 & 9 & 11 \\
\hline Informed consent for diagnostic examinations & 2.2 & 1.2 & 41 & 23 & 20 & 10 & 6 \\
\hline Information about health status & 2.2 & 1.2 & 41 & 25 & 17 & 13 & 4 \\
\hline Informed consent for treatment & 2.2 & 1.2 & 39 & 24 & 24 & 8 & 5 \\
\hline Quality health care & 2.0 & 1.2 & 52 & 19 & 14 & 10 & 5 \\
\hline Access to the medical file & 2.0 & 1.3 & 51 & 20 & 13 & 9 & 7 \\
\hline Care in patients' own language & 2.0 & 1.4 & 56 & 6 & 5 & 6 & 12 \\
\hline Respect for privacy & 1.8 & 1.2 & 57 & 20 & 12 & 6 & 5 \\
\hline Free choice of hospital & 1.8 & 1.2 & 59 & 21 & 11 & 4 & 6 \\
\hline Free choice of care provider & 1.8 & 1.1 & 59 & 19 & 11 & 7 & 4 \\
\hline Dignified end-of-life & 1.7 & 1.1 & 66 & 13 & 12 & 5 & 4 \\
\hline Complaints mediation & 1.7 & 1.1 & 67 & 12 & 13 & 5 & 3 \\
\hline Free choice of specialist & 1.7 & 1.1 & 59 & 21 & 12 & 3 & 5 \\
\hline Palliative care & 1.6 & 1.1 & 71 & 11 & 9 & 7 & 2 \\
\hline Euthanasia & 1.6 & 1.0 & 70 & 12 & 10 & 5 & 3 \\
\hline Self determination & 1.6 & 1.0 & 68 & 14 & 12 & 3 & 3 \\
\hline Protection of a person with a mental illness & 1.6 & 1.0 & 68 & 14 & 12 & 2 & 4 \\
\hline Free choice of family physician & 1.4 & 0.9 & 76 & 12 & 8 & 2 & 2 \\
\hline Abortion & 1.3 & 0.7 & 84 & 9 & 5 & 1 & 1 \\
\hline Protection of life & 1.2 & 0.6 & 88 & 6 & 5 & 0 & 1 \\
\hline
\end{tabular}

\section{RESULTS}

\section{Participants}

A total of 1,732 of the invited persons visited the website, 707 started to answer the questionnaire, and 309 persons completed all 20 questions. The mean age of participants who completed all questions was 46 years, $58 \%$ of them were women. Most of the participants lived in urban areas (44\%), 35\% lived in rural areas and $21 \%$ lived in semi-rural areas. The highest educational level achieved by participants was most often university education (42\%), followed by higher education (33\%), secondary education (24\%), and primary education ( $1 \%)$.

\section{Importance of Patients' Rights}

All patients' rights scored very high in terms of importance. The lowest scores on the Likert scale were almost never used for any of the patients' rights. The mean score on a scale from 1 to 5 was 4.6 with SD 0.2. According to the surveyed sample of the population, the most important patients' rights were dignified end-of-life, affordable health care, information about health status, euthanasia, quality of health care, and palliative care. These six patients' rights all scored 4.8 or more. More than $80 \%$ of participants gave them the highest score on the Likert scale. The patients' rights with the lowest importance were protection of life and free choice of care provider. Less than $60 \%$ of participants gave both rights the highest score on the Likert scale.
When comparing the importance of patients' rights between Dutch- and French-speaking participants, the latter attached more importance to the right of complaints mediation and to the right of free choice of hospital.

\section{Perceived Protection by Patients' Rights}

The protection that patients' rights provide was perceived to be relatively low. The mean score was 3.3 with SD 0.3 . The protection by patients' rights was perceived to be the highest in respect of the free choice of a family physician, protection of life and abortion. More than $20 \%$ of participants gave the highest score to these rights. The protection by patients' rights was perceived to be the lowest in respect to affordable health care, euthanasia and care offered in the patient's own language. This last right received the lowest score from one in five participants.

When comparing the perceived protection by patients' rights between Dutch- and French-speaking participants, the latter felt better protected by laws concerning informed consent, diagnostic examinations and treatments, and the laws covering the dignified end-of-life. The Dutch-speaking participants felt better protected by the right to affordable health care.

\section{Problems with Patients' Rights}

Participants generally experienced very few problems with patients' rights. The mean score was 1.8 with SD 0.3. Participants declared to experience most of their problems in respect of the affordability of health care, informed consent for diagnostic 
Table 4. Mean scores on a Likert scale from 1 to 5 and the standard deviations for all 20 rights comparing Dutch-speaking and French-speaking participants

\begin{tabular}{|c|c|c|c|}
\hline & $\begin{array}{l}\text { Dutch-speaking } \\
\text { mean (SD) }\end{array}$ & $\begin{array}{c}\text { French-speaking } \\
\text { mean (SD) }\end{array}$ & $\mathrm{p}$-value \\
\hline \multicolumn{4}{|l|}{ The right to high quality health care } \\
\hline How much importance do you attach to this right? & $4.8(0.5)$ & $4.8(0.4)$ & 1.000 \\
\hline How well protected do you feel in this by the law? & $3.5(1.3)$ & $3.3(1.4)$ & 0.548 \\
\hline Have you already had problems with this right? & $1.9(1.2)$ & $1.9(1.2)$ & 0.963 \\
\hline \multicolumn{4}{|l|}{ The right to free choice of care provider } \\
\hline How much importance do you attach to this right? & $4.2(0.9)$ & $4.4(0.8)$ & 0.251 \\
\hline How well protected do you feel in this by the law? & $3.5(1.3)$ & $3.3(1.5)$ & 0.402 \\
\hline Have you already had problems with this right? & $1.8(1.1)$ & $1.8(1.2)$ & 0.842 \\
\hline \multicolumn{4}{|l|}{ The right to information about health status } \\
\hline How much importance do you attach to this right? & $4.8(0.6)$ & $4.8(0.4)$ & 0.761 \\
\hline How well protected do you feel in this by the law? & $3.4(1.3)$ & $3.5(1.3)$ & 0.835 \\
\hline Have you already had problems with this right? & $2.2(1.2)$ & $2.2(1.1)$ & 0.817 \\
\hline \multicolumn{4}{|c|}{ The right to informed consent for diagnostic examinations } \\
\hline How much importance do you attach to this right? & $4.7(0.7)$ & $4.7(0.7)$ & 0.746 \\
\hline How well protected do you feel in this by the law? & $3.3(1.4)$ & $3.8(1.3)$ & 0.039 \\
\hline Have you already had problems with this right? & $2.2(1.2)$ & $2.2(1.2)$ & 0.856 \\
\hline \multicolumn{4}{|l|}{ The right to informed consent for treatments } \\
\hline How much importance do you attach to this right? & $4.7(0.6)$ & $4.7(0.6)$ & 1.000 \\
\hline How well protected do you feel in this by the law? & $3.3(1.4)$ & $3.8(1.3)$ & 0.040 \\
\hline Have you already had problems with this right? & $2.2(1.2)$ & $2.1(1.1)$ & 0.485 \\
\hline \multicolumn{4}{|l|}{ The right to access to the medical file } \\
\hline How much importance do you attach to this right? & $4.5(0.9)$ & $4.6(1.0)$ & 0.799 \\
\hline How well protected do you feel in this by the law? & $3.4(1.4)$ & $3.3(1.5)$ & 0.702 \\
\hline Have you already had problems with this right? & $2.0(1.3)$ & $2.1(1.3)$ & 0.725 \\
\hline \multicolumn{4}{|l|}{ The right to respect for privacy } \\
\hline How much importance do you attach to this right? & $4.6(0.7)$ & $4.8(0.4)$ & 0.070 \\
\hline How well protected do you feel in this by the law? & $3.6(1.3)$ & $3.6(1.4)$ & 0.934 \\
\hline Have you already had problems with this right? & $1.9(1.2)$ & $1.5(0.7)$ & 0.047 \\
\hline \multicolumn{4}{|l|}{ The right to complaints mediation } \\
\hline How much importance do you attach to this right? & $4.5(0.8)$ & $4.8(0.5)$ & 0.037 \\
\hline How well protected do you feel in this by the law? & $3.2(1.6)$ & $3.1(1.6)$ & 0.887 \\
\hline Have you already had problems with this right? & $1.7(1.1)$ & $1.4(0.9)$ & 0.120 \\
\hline \multicolumn{4}{|l|}{ The right to palliative care } \\
\hline How much importance do you attach to this right? & $4.8(0.6)$ & $4.9(0.3)$ & 0.216 \\
\hline How well protected do you feel in this by the law? & $3.4(1.4)$ & $3.5(1.5)$ & 0.645 \\
\hline Have you already had problems with this right? & $1.6(1.1)$ & $1.5(1.0)$ & 0.471 \\
\hline \multicolumn{4}{|l|}{ The right to the dignified end-of-life } \\
\hline How much importance do you attach to this right? & $4.9(0.5)$ & $4.8(0.5)$ & 0.809 \\
\hline How well protected do you feel in this by the law? & $2.9(1.7)$ & $3.5(1.4)$ & 0.035 \\
\hline Have you already had problems with this right? & $1.7(1.1)$ & $1.5(0.9)$ & 0.223 \\
\hline \multicolumn{4}{|l|}{ The right to euthanasia } \\
\hline How much importance do you attach to this right? & $4.8(0.6)$ & $4.8(0.5)$ & 0.575 \\
\hline How well protected do you feel in this by the law? & $2.9(1.6)$ & $3.1(1.5)$ & 0.329 \\
\hline Have you already had problems with this right? & $1.6(1.1)$ & $1.4(0.9)$ & 0.262 \\
\hline \multicolumn{4}{|l|}{ The right to self determination } \\
\hline How much importance do you attach to this right? & $4.7(0.6)$ & $4.7(0.8)$ & 1.000 \\
\hline How well protected do you feel in this by the law? & $3.3(1.4)$ & $3.6(1.4)$ & 0.230 \\
\hline Have you already had problems with this right? & $1.6(1.0)$ & $1.2(0.6)$ & 0.023 \\
\hline
\end{tabular}


Table 4. Mean scores on a Likert scale from 1 to 5 and the standard deviations for all 20 rights comparing Dutch-speaking and French-speaking participants (Continued)

\begin{tabular}{|c|c|c|c|}
\hline & $\begin{array}{l}\text { Dutch-speaking } \\
\text { mean (SD) }\end{array}$ & $\begin{array}{l}\text { French-speaking } \\
\text { mean (SD) }\end{array}$ & p-value \\
\hline \multicolumn{4}{|l|}{ The right to abortion } \\
\hline How much importance do you attach to this right? & $4.6(0.9)$ & $4.6(0.8)$ & 0.698 \\
\hline How well protected do you feel in this by the law? & $3.7(1.3)$ & $3.4(1.7)$ & 0.142 \\
\hline Have you already had problems with this right? & $1.3(0.7)$ & $1.1(0.4)$ & 0.269 \\
\hline \multicolumn{4}{|l|}{ The right to protection of life } \\
\hline How much importance do you attach to this right? & $4.3(1.0)$ & $4.5(1.1)$ & 0.333 \\
\hline How well protected do you feel in this by the law? & $3.7(1.3)$ & $3.7(1.6)$ & 0.903 \\
\hline Have you already had problems with this right? & $1.2(0.6)$ & $1.1(0.5)$ & 0.352 \\
\hline \multicolumn{4}{|l|}{ The right to care in the patients' own language } \\
\hline How much importance do you attach to this right? & $4.5(0.8)$ & $4.4(1.0)$ & 0.509 \\
\hline How well protected do you feel in this by the law? & $2.5(1.7)$ & $3.0(1.7)$ & 0.130 \\
\hline Have you already had problems with this right? & $2.2(1.5)$ & $1.3(0.6)$ & $<0.001$ \\
\hline \multicolumn{4}{|l|}{ The right to free choice of family physician } \\
\hline How much importance do you attach to this right? & $4.5(0.8)$ & $4.7(0.5)$ & 0.091 \\
\hline How well protected do you feel in this by the law? & $3.8(1.2)$ & $3.7(1.4)$ & 0.615 \\
\hline Have you already had problems with this right? & $1.4(0.9)$ & $1.3(0.7)$ & 0.259 \\
\hline \multicolumn{4}{|l|}{ The right to free choice of specialist } \\
\hline How much importance do you attach to this right? & $4.4(0.9)$ & $4.7(0.7)$ & 0.092 \\
\hline How well protected do you feel in this by the law? & $3.5(1.4)$ & $3.6(1.6)$ & 0.464 \\
\hline Have you already had problems with this right? & $1.8(1.1)$ & $1.6(1.1)$ & 0.514 \\
\hline \multicolumn{4}{|l|}{ The right to free choice of hospital } \\
\hline How much importance do you attach to this right? & $4.5(0.9)$ & $4.7(0.6)$ & 0.017 \\
\hline How well protected do you feel in this by the law? & $3.3(1.6)$ & $3.5(0.5)$ & 0.140 \\
\hline Have you already had problems with this right? & $1.8(1.2)$ & $1.5(0.9)$ & 0.018 \\
\hline \multicolumn{4}{|l|}{ The right to affordable health care } \\
\hline How much importance do you attach to this right? & $4.8(0.5)$ & $4.8(0.6)$ & 0.251 \\
\hline How well protected do you feel in this by the law? & $3.0(1.5)$ & $2.5(1.5)$ & 0.004 \\
\hline Have you already had problems with this right? & $2.2(1.4)$ & $2.3(1.3)$ & 0.571 \\
\hline \multicolumn{4}{|c|}{ The right to protection of persons with a mental illness } \\
\hline How much importance do you attach to this right? & $4.5(0.7)$ & $4.4(1.0)$ & 0.294 \\
\hline How well protected do you feel in this by the law? & $3.3(1.5)$ & $3.3(1.7)$ & 0.714 \\
\hline Have you already had problems with this right? & $1.6(1.1)$ & $1.6(0.9)$ & 0.730 \\
\hline
\end{tabular}

examinations, information about health status, and informed consent for treatment. Participants declared to experience almost no problems with the free choice of a family physician, laws concerning abortion or protection of life.

When comparing the perceived problems with patients' rights between Dutch- and French-speaking participants, the former perceived more problems with right concerning the respect of privacy, self determination, receiving care in the patient's own language, and the right to free choice of hospital as well.

\section{DISCUSSION}

\section{Strengths and Weaknesses of the Study}

The design of the study excluded participants without access to the Internet. This might bias the representativeness of participants.
However, the worldwide expansion of access to and use of the Internet over the last two decades has made the World Wide Web a prominent mode of communication and receives an increasing attention in the social and health sciences (10).

Data from the Belgian National Institute of Statistics show that Belgium had 3.15 million Internet connections in the first quarter of 2010. The number of connections does not necessarily match the number of users as one connection can be used by different users. The rapid rise of the Internet certainly opens new areas of investigation for social science researchers and will reduce the bias caused by the Internet inaccessibility.

The high proportion of visitors who did not start the questionnaire is remarkable. Less than $50 \%$ started the questionnaire, while less than $20 \%$ of all visitors finished it. This low response rate may be related to the monotony of the questionnaire, repeating the same three sub-questions for each of the 20 different patients'rights that were questioned. 
There was an overrepresentation of highly educated participants living in urban areas. This may be related to the methodology of Internet-based questionnaires, response rates being higher among interested Internet users who are more often highly educated and live in urban regions.

The results were standardised for age, gender, education, and area of living, in an effort to eliminate participation biases. However, less than $20 \%$ of the website visitors completed the questionnaire. This could lead to an important selection bias. Highly educated people, who are probably more interested in patients' rights, are overrepresented in the study. Our method for standardizing respondents according to the Belgian population is only adequate to control for their educational level but not for their interest in patients' rights.

\section{Perceptions of Patients' Rights}

All patients' rights were considered to be very important. The most important patients' rights were the right to dignified end-of-life care, affordable health care, information about health status, euthanasia, quality of health care, and palliative care. None of the patients' rights received a low score. The protection of life and free choice of care provider received the relatively lowest scores.

The participants perceived protection by patients' rights to be quite low. They perceive a fair protection only in respect to the free choice of family physician, protection of life and abortion. The participants had worries about the affordability of health care, euthanasia and care offered in the patient's own language.

Many participants were also concerned about the end-of-life care and care provided in the patient's own language. The first concern is surprising because Belgium is one of only three countries in the world that has a law regulating euthanasia enacted 2002, and receives regular media attention. The law guarantees that patients with irresolvable and unbearable physical or psychological suffering can receive euthanasia upon personal informed request. However, the law does not apply to persons with advanced dementia or minors because they cannot give official consent.

On the other hand, in Belgium and many other countries an informed consent is not needed for terminal sedation. Some authors even state that it is neither useful nor meaningful to ask for the patient's informed consent (11). This legal gap between euthanasia and terminal sedation leads to great juridical uncertainty for patients and physicians.

Despite the existence of law concerning palliative care (14 June, 2002), end-of-life care as such is not covered by any Belgian law. People might be worried because in Belgium many patients are transferred to a nursing home during the last years of their life and many are transferred to hospitals during the last days of their life, making end-of-life care an important issue to patients (12).

In view of the legislation concerning patients' rights, including euthanasia and the protection of the mentally ill, it often becomes difficult to act in an appropriate way. For example, patients refusing medical treatment after a failed suicide attempt may exercise the right to refuse treatment (13).

Care offered in the patient's own language is another major concern of the participants. In Belgium, medical care provided in the patient's own language is not legally bound nor ethically obliged by the Board of Physicians. In the United States, as in many other countries, the right to health care in one's own language is included in the constitution. As it is not often possible for physicians, nurses and other health care providers to speak all official Belgian languages as well as additional languages of people coming from abroad, most of the Belgian hospitals use interpreters to guarantee health care in the patients' own language. This is a problem that mainly occurs in the cities with a great ethnic diversity, especially in Brussels and its surroundings. In Brussels, most of the physicians speak French and are not able to provide medical care in Dutch to the Dutch-speaking minority. These French-speaking physicians are also responsible for the mobile emergency interventions in the surroundings of Brussels where a majority of Dutch-speaking inhabitants are living, thus making the problem even worse. The results from this study point to the desirability of a legal solution for this linguistic problem.

Although participants perceived their rights as very important and perceived a lack of protection by existing laws, very few participants had experienced problems with patients' rights. Most of the reported problems were related to the affordability of health care, informed consent for diagnostic examinations, information about health status, and informed consent for treatment. Very few patients experienced problems with the free choice of family physicians, abortion or protection of life.

The perceived problems with the affordability of health care, informed consent for diagnostic examinations and treatments, and information about health status are surprising. Belgium has a very accessible health care insurance system guaranteeing affordable high-quality health care for all inhabitants. Moreover, there is a very effective social safety system for inhabitants and refugees who cannot apply for regular health care insurance. On the other hand, affordability problems are probably due to the fact that Belgium has quite high copayment level. The affordability of health care is a main issue in many countries. In the United States, the Patient Protection and Affordable Care Act was signed by Barack Obama on 23 March 2010. It should make health coverage more available and affordable, especially for cancer patients and survivors (14).

The procedures concerning informed consent and information about health status are covered by the law which came into force on 22 August 2002. However, a study of Schoonacker and Louckx confirmed that patients' rights were insufficiently acknowledged by physicians and nurses, therefore, patients' rights were not always respected $(15,16)$. Most of the physicians and nurses were not familiar enough with the law and they experienced problems communicating most aspects of it. Most patients were well informed about the treatment procedures. However, they were not often informed about alternative diagnostic procedures and treatments, nor were they sufficiently informed about the cost of their treatment for the community and themselves. Most of the physicians and nurses knew that an informed consent of patient is necessary for diagnostic procedures and treatments and they had good knowledge of the right to inspect or copy patient files $(15,16)$.

\section{Comparison between Dutch- and French-speaking Participants}

The French-speaking participants attached more importance to the right to complaints mediation and the right to free choice 
of hospital. They also felt better protected by the laws concerning informed consent for diagnostic examinations and treatments and the laws concerning the dignified end-of-life. The Belgian laws concerning patients' rights are identical for both linguistic groups. The differences are probably related to cultural differences and differences in perception. However, the perception by Frenchspeaking participants of better protection for examinations, treatments and the end-of-life decisions are surprising, knowing that in the French-speaking community for example some cases of euthanasia are not reported to the evaluation commission (17).

The Dutch-speaking participants felt better protected in respect of the right to affordable health care but they perceived more problems regarding the right to privacy, self determination, care received in the patient's own language, and the free choice of hospital. These results are not surprising since the standard of living and the level of wealth are significantly higher in the Dutch-speaking community. But Dutch-speaking participants, mainly those living in Brussels and suburbs, reported problems with receiving health care in Dutch, mainly when transferred to emergency departments. Patients who need urgent medical care often cannot choose the hospital they are transferred to because they are transferred to the nearest hospital which is often a hospital with French-speaking physicians only.

\section{Comparison with Other Studies}

It is difficult to compare the results of this study with studies conducted in other countries since the laws differ. The laws are adapted to the specific situation in health care provision and organisation in particular country. In the US, state laws differ somewhat between different states, e.g. laws concerning psychiatric patients (18).

Although our research seems unique in the European countries, some similar research can be found outside Europe.

Three years after a patients' rights regulation was passed in Turkey in 1998, only $9 \%$ of patients were aware of this regulation (19). The patients who stated that they had not received care in accordance with their rights identified the shortcomings as not receiving written $(95 \%)$ or verbal $(53 \%)$ information from healthcare professionals, and healthcare personnel who did not introduce themselves $(75 \%)$. Turkish cancer patients attached the great importance to the right to be informed (87\%) and that the physician should inform the patient on the diagnosis and the treatment (92\%) (20).

In Spain, only $5 \%$ of elderly patients confirmed that they had been asked whether information could be given to their relatives (21). Most of the physicians had doubts about the capacity of elderly patients to participate in the decision-making process.

In Malaysia, $90 \%$ of hospitalized patients were aware of their rights, but treatment options were discussed in $45 \%$ of cases only (22).

\section{Future Research}

Several patients' rights were not questioned in our study. For example, the problem of elder abuse was not included in the questionnaire, even though this problem is preventable and seems to become increasingly important during the coming years (23).

Organ donation and allocation was not included either, even though this topic has been the subject of recent discussions in many countries that are considering change of the methods for procuring and distributing human organs for transplantation (24). In Belgium, the law on removal and transplantation of organs regulated this matter from 13 June 1986.

Another issue that we did not address is e-mail communication between physicians and patients, even though this is a potential tool for improvement of physician-patient communication and patient care. However, the use of e-mail is not yet well established. Precautions are needed in order to protect the privacy of physicians and patients (25). The same precautions are needed for health care providers using social media such as Facebook. They should remain mindful of professional boundaries and patients' privacy rights (26).

Also, patients' rights of minor children were not included in our questionnaire. Several problematic situations with minors exist such as the right of free choice of a physician and the right of the minor to obtain informational privacy. In case of a divorce, the situation is even more difficult (27). Family physicians as well as paediatricians may for instance encounter situations in which "proxy consent" for urgent and non-urgent medical care for minors is needed (28).

The right to spiritual care was not questioned. Spiritual care is often interpreted as giving professional attention to the particular spiritual and religious beliefs of patients (29).

The conditions under which medical information should be accessible for research were not questioned. It is an important topic in many countries (30). Laws to protect individual privacy have hampered the flow of health care data for research purposes and increased costs and delays, affecting the quality and timeliness of analysis. In Australia for instance, excessive privacy regulations had a negative effect on public health research (31). In the study of Lane and Schur, the authors recommended reducing delays in access to data for research and increasing the use of remote access data enclaves to guarantee health service research (32).

In Belgium, the e-Health platform was established by law on 21 August 2008. It is the official federal network devoted to secure health data exchange in many types of applications such as health care purposes, the simplification of administrative procedures and contribution to health policy (33). Recent laws on privacy, patients' rights and euthanasia have contributed to behavioural change in citizens' and physicians' attitudes with regard to data exchange and storage. We have to be aware that excessive regulation can create barriers to appropriate patient treatment as well as health service research (34).

\section{CONCLUSIONS}

The affordability of health care is the most important concern of all participants. This is remarkable, knowing that Belgium has a very accessible health care insurance system. Many participants are concerned about end-of-life care and care provided in the patients' own language. Although Belgium is one of three countries in the world with a law regulating end-of-life care and euthanasia, people are concerned about the quality of care during the last phase of life. Care provided in the patients' own language should be legally regulated to ensure high-quality health care for all inhabitants. 


\section{Acknowledgement}

The authors thank to all participating patient organisations and health insurance services as well as the participators for completing the questionnaire.

\section{Ethical Approval}

The study protocol was approved by the Ethical Committee of the University Hospital of Brussels (UZ Brussel).

\section{Conflict of Interest}

None declared

\section{REFERENCES}

1. Vision of the patient to significant developments in health. The law on the rights of the patient - the patient as an expert. Sint-Truiden: Ziekeren Psychiatric Center, 2004. (In Dutch.)

2. Dijkhoffz HW. Annual report of the Dutch-speaking federal mediator for the rights of the patient. Brussels: Federal Public Service for Health, Food Chain Safety and Environment; 2004. (In Dutch.)

3. Gryson S, Verhaegen MN, Wilmotte R, Debreyne V. Annual report of the Dutch-speaking federal mediator for the rights of the patient. Brussels Federal Public Service for Health, Food Chain Safety and Environment; 2008. (In Dutch.)

4. Deneyer M, De Groot E, Decreton S, Verheijen P, Van den Brande P, Broos P. Deontological aspects of medicine, more specifically for the surgeon in a changing social environment. Acta Chir Belg. 2009 NovDec;109(6):670-3.

5. Gryson S, Verhaegen MN, Wilmotte R, Debreyne V. Annual report of the Dutch-speaking federal mediator for the rights of the patient. Brussels: Federal Public Service for Health, Food Chain Safety and Environment; 2006. (In Dutch.)

6. Gryson S, Verhaegen MN, Wilmotte R, Debreyne V. Annual report of the Dutch-speaking federal mediator for the rights of the patient. Brussels Federal Public Service for Health, Food Chain Safety and Environment; 2007. (In Dutch.)

7. Claudot F, Alla F, Villemot JP, Aliot E, Coudane H, Juillière Y. Analysis of patient claims related to care in a university cardiology department over the period 2003-2007. Arch Cardiovasc Dis. 2010 NovDec;103(11-12):595-602.

8. Survey of patient rights. Brussels: Socialist Mutual; 2008. (In Dutch.)

9. Statistics Belgium [Internet]. Brussels: Belgian Federal Government; 2011. Structure of the Belgian population in 2010; [cited 2011 Mar 1]. Available from: http://statbel.fgov.be/nl/statistieken/cijfers/bevolking/ structuur/index.jsp. (In Dutch.)

10. Tates K, Zwaanswijk M, Otten R, van Dulmen S, Hoogerbrugge PM, Kamps WA, et al. Online focus groups as a tool to collect data in hardto-include populations: examples from paediatric oncology. BMC Med Res Methodol. 2009 Mar 3;9:15.

11. Krishna L. Consent in terminal sedation. Indian J Med Ethics. 2010 JulSep;7(3):161-4.

12. Van den Block L, Deschepper R, Bossuyt N, Drieskens K, Bauwens S, Van Casteren V, et al. Care for patients in the last months of life: the Belgian Sentinel Network Monitoring End-of-Life Care study. Arch Intern Med. 2008 Sep 8;168(16):1747-54.

13. Ryan CJ, Callaghan S. Legal and ethical aspects of refusing medical treatment after a suicide attempt: the Wooltorton case in the Australian context. Med J Aust. 2010 Aug 16;193(4):239-42.
14. Schwartz K, Claxton G. The patient protection and affordable care act: how will it affect private health insurance for cancer patients? Cancer J. 2010 Nov-Dec;16(6):572-6.

15. Schoonacker M, Louckx F. The law on patients' rights: knowledge, use and attitudes among professionals (doctors, specialists and nurses). Haverlee: Flemish Patients' Platform; 2006. (In Dutch.)

16. Schoonacker M, Louckx F. The law on patients' rights: communication with the patient. A study among general practitioners in Flanders. Haverlee: Flemish Patients' Platform; 2007. (In Dutch.)

17. Van den Block L, Deschepper R, Bilsen J, Bossuyt N, Van Casteren V, Deliens L. Euthanasia and other end-of-life decisions: a mortality followback study in Belgium. BMC Public Health. 2009 Mar 9;9:79.

18. Cady RF. A review of basic patient rights in psychiatric care. JONAS Healthc Law Ethics Regul. 2010 Oct-Dec;12(4):117-25.

19. Kuzu N, Ergin A, Zencir M. Patients' awareness of their rights in a developing country. Public Health. 2006 Apr;120(4):290-6.

20. Erer S, Atici E, Erdemir AD. The views of cancer patients on patient rights in the context of information and autonomy. J Med Ethics. 2008 May;34(5):384-8.

21. Pérez-Cárceles MD, Lorenzo MD, Luna A, Osuna E. Elderly patients also have rights. J Med Ethics. 2007 Dec;33(12):712-6.

22. Yousuf RM, Fauzi AR, How SH, Akter SF, Shah A. Hospitalised patients' awareness of their rights: a cross-sectional survey from a tertiary care hospital on the east coast of Peninsular Malaysia. Singapore Med J. 2009 May;50(5):494-9.

23. Fraser A. Preventing abuse of older people. Nurs Manag (Harrow). 2010 Oct;17(6):26-9.

24. Pope TM. Legal briefing: organ donation and allocation. J Clin Ethics. 2010 Fall;21(3):243-63.

25. Boukus ER, Grossman JM, O'Malley AS. Physicians slow to e-mail routinely with patients. Issue Brief Cent Stud Health Syst Change. 2010 Oct:(134):1-5.

26. Hader AL, Brown ED. Patient privacy and social media. AANA J. 2010 Aug;78(4):270-4.

27. Deneyer M, Clybouw C, De Groot E, De Backer A, Van den Brande P Vandenplas Y. The Surgeon and the Law on Patient's Rights for Minors. Acta Chir Belg. 2011 May-Jun;111(3):119-24.

28. McAbee GN. Committee on Medical Liability and Risk Managemen American Academy of Pediatrics. Consent by proxy for nonurgent pediatric care. Pediatrics. 2010 Nov;126(5):1022-31.

29. VandeCreek L. Defining and advocating for spiritual care in the hospital. J Pastoral Care Counsel. 2010 Summer;64(2):5.1-10.

30. Rosenbaum S. Data governance and stewardship: designing data stewardship entities and advancing data access. Health Serv Res. 2010 Oct;45(5 Pt 2):1442-55

31. O'Keefe CM, Connolly CJ. Privacy and the use of health data for research. Med J Aust. 2010 Nov 1;193(9):537-41.

32. Lane J, Schur C. Balancing access to health data and privacy: a review of the issues and approaches for the future. Health Serv Res. 2010 Oct;45(5 Pt 2):1456-67.

33. France FR. eHealth in Belgium, a new "secure" federal network: role of patients, health professions and social security services. Int J Med Inform. 2011 Feb;80(2):e12-6.

34. Ferreira A, Correia R, Chadwick D, Antunes L. Access control in healthcare: the methodology from legislation to practice. Stud Health Technol Inform. 2010;160(Pt 1):666-70. 